\title{
Incubator Analyzer Portabel Berbasis Pemrograman Visual Dilengkapi Penyimpanan ke $S d$ Card
}

\author{
(Parameter Suhu Dan Air Flow)
}

\author{
Agistya Ananda Charisa ${ }^{\#}$, Bedjo Utomo, Syaifudin \\ Department of Electromedical Engineering Poltekkes Kemenkes, Surabaya \\ Jl. Pucang Jajar Timur No. 10, Surabaya, 60245, Indonesia \\ \#agistya.ananda12@gmail.com, bedjoutomo123@gmail.com,nyong74@yahoo.com.
}

\begin{abstract}
Abstrak - Menurut peraturan pemerintah, alat kesehatan yang digunakan di sarana pelayanan kesehatan wajib untuk dilakukan uji kalibrasi secara berkala, setidaknya satu tahun sekali. Salah satu contoh alat yang digunakan untuk kalibrasi adalah Incubator Analyzer. Tujuan umum penulisan karya tulis ilmiah ini adalah untuk menganalisis hasil data pengukuran suhu dan air flow modul incubator analyzer dengan INCU test II. Tujuan khusus penulisan karya tulis ilmiah ini adalah melakukan analisis data suhu dan air flow dengan metode after only. Suhu adalah derajat panas atau dingin yang diukur berdasarkan skala tertentu dengan menggunakan thermometer. Sedangkan Air flow meter, adalah perangkat yang mengukur aliran udara, yaitu berapa banyak udara mengalir melalui tabung. Ini tidak mengukur volume udara yang lewat melalui tabung, mengukur kecepatan yang sebenarnya dari udara yang mengalir melalui perangkat dalam segmen waktu yang ditetapkan. Sensor DS18B20 dapat mendeteksi suhu dengan cukup baik dimana didapatkan error terbesar pada DS18B20 $0,071372741 \%$, pada sensor ultrasound dapat mendeteksi airflow dengan error $0,6 \%$. Menggunakan pengiriman data dengan Bluetooth HC-05 yang ditampilkan pada pemrograman Delphi. Dari data yang dihasilkan dapat disimpulkan bahwa alat laik digunakan.
\end{abstract}

Kata Kunci-Incubator Analyzer; DS18B20;Ultrasound.

\section{Pendahuluan}

Alat ukur atau instrumen, dari segi kemampuan harus mengandung ketelitian dan ketepatan. Ketelitian (accuracy) adalah harga terdekat dengan mana suatu pembacaan instrumen mendekati harga sebenarnya dari variabel yang diukur. Ketepatan (precision) adalah suatu ukuran kemampuan untuk mendapatkan hasil pengukuran yang serupa. Setiap instrumen ukur dapat dianggap baik apabila telah dibuktikan dengan suatu pengujian alat, yang disebut dengan kalibrasi alat.[1]

Arti kalibrasi menurut ISO/IEC Guide 17025 adalah serangkaian kegiatan yang membentuk hubungan antara nilai yang ditunjukkan oleh instrumen ukur atau sistem pengukuran, atau nilai yang diwakili oleh bahan ukur, dengan nilai-nilai yang sudah diketahui yang berkaitan dari besaran yang diukur dalam kondisi tertentu.

Dengan kata lain, kalibrasi adalah kegiatan untuk menentukan kebenaran konvensional nilai penunjukkan alat ukur dan bahan ukur dengan cara membandingkan terhadap standar ukur yang mampu telusur (traceable) ke standar nasional untuk satuan ukuran dan/atau internasional.

Sistem manajemen baik itu sistem manajemen mutu ISO 9001 : 2008, sistem manajemen lingkungan ISO 14001:2005, ataupun sistem manajemen kesehatan keselamatan kerja OHSAS 18001 : 2008 juga mempersyaratkan dalam salah satu klausulnya bahwa peralatan yang digunakan dalam suatu perusahaan yang berpengaruh terhadap mutu, lingkungan, ataupun kesehatan harus dikalibrasi ataupun diverifikasi secara berkala.

Incubator Analyzer merupakan perangkat yang dirancang dan dibangun untuk memverifikasi pengoperasian dan kondisi lingkungan Baby Incubator yang dapat melakukan perekaman parameter seperti aliran udara/air flow, kebisingan/noise, suhu/temperature, dan kelembaban relatif/relative humidity. [2]

Baby incubator harus mempunyai sistem yang terkontrol atau mempunyai kelembaban relatif dan isolasi untuk melindungi bayi terkontaminasi udara dari luar. Hal ini diperlukan bagi bayi prematur karena sangat rawan terhadap masalah pernapasan dan masalah-masalah yang bersangkutan dengan kesehatan bayi tersebut. Suhu yang dibutuhkan dalam perawatan bayi ini antara $32^{\circ} \mathrm{C}-37^{\circ} \mathrm{C}$.

Menurut pengamatan penulis pada alat incubator analyzer yang ada di laboratorium kalibrasi Teknik Elektromedik Surabaya pada saat digunakan praktek pengukuran (kalibrasi) pada waktu melihat nilai per-parameter, pintu inkubator bayi harus dibuka tutup yang dapat berdampak pada kebocoran suhu dan ketidakstabilan pengukuran per parameter. Dalam melakukan proses pengukuran per-parameter harus secara bergantian karena, hanya menggunakan 1 display. Proses pengambilan data seperti ini membutuhkan waktu yang lama. (pengalaman praktikum di lab. kalibrasi teknik elektromedik).

Untuk meminimalisir hal tersebut, maka diharapkan hasil pengukuran dalam Incubator Analyzer dapat ditampilkan pada 
Personal Computer dengan pengiriman melalui Bluetooth satu persatu parameternya. [3]

Penulis disini menambahkan penyimpanan SD Card dan agar saat proses kalibrasi data dapat disimpan di SD Card jika sewaktu-waktu PC/laptop user mati.

Dari dasar-dasar seperti itulah penulis mencoba membuat alat "Incubator Analyzer Portable Wireless Via PC dengan penyimpanan $S D$ Card" dengan dilengkapi pengiriman data melalui Bluetooth yang ditampilkan ke PC dengan penyimpanan data berupa SD Card, dengan parameter suhu dan airflow.

Alat Incubator Analyzer sebelumnya pernah dibuat oleh Ericka Helen Reynilda dan Vina Alfi Madidah (2016) alat ini sudah portable dengan menggunakan tampilan PC, namun masih terdapat kekurangan yaitu tidak bisa menyimpan data sehingga ketika pengukuran selesai, operator harus menulis ulang untuk di masukkan ke lembar kerja perhitungan kalibrasi. Lalu dikembangakan oleh Rizka Nur Uswatun dan Dimas Alief Juniar R (2018) alat ini sudah portable dengan menggunakan tampilan PC dengan pengiriman Via Bluetooth, namun masih terdapat kekurangan yaitu Pada PC menunjukkan nilai rata-rata kelembaban sebesar $0,26 \mathrm{~m} / \mathrm{sec}$ dan pada Incubator Analyzer II menunjukkan nilai rata-rata sebesar $0,1 \mathrm{~m} / \mathrm{sec}$. Sehingga, dari hasil data rata-rata Air Flow pada PC dan Incubator Analyzer II didapatkan error sebesar $62,025316 \%$ Error ini di dapatkan dari hasil banding dengan Incubator Analyzer II.

Pengambilan data yang saat ini digunakan oleh hampir semua petugas kalibrasi adalah dengan mengamati selang waktu beberapa menit lalu setelah itu dilakukan lah perhitungan pada incubator seperti standar deviasi. Dan pada umumnya incubator analyzer hanya menampilkan 1 display pengukuran sehingga jika pengamatan di lakukan 10 kali setiap beberapa menit sekali akan membutuhkan waktu yang cukup lama karena ada beberapa parameter yang perlu diamati juga.

Dalam penelitian ini penulis melakukan analisa terhadap keakuarasian hasil data dari penyimpanan di SD Card dan hasil dari tampilan PC. Dan Penulis disini akan menambahkan penyimpanan SD Card agar saat mengkalibrasi tiba-tiba baterai habis, bisa disimpan di SD Card karena jika alat terhubung dengan Bluetooth baterai alat cepat habis. Sehingga penggunaan alat kurang optimal.

\section{MATERI DAN Metode}

\section{A. Pengaturan Eksperimen}

Penelitian ini menggunakan subjek Baby Incubator. Pengambilan sampel tersebut dilakukan secara acak dengan pengambilan data sebanyak untuk dikirim ke aplikasi Delphi dan $S D$ card secara bersamaan setiap 6 menit sebanyak 6 kali.

\section{1) Material dan Alat}

Penelitian ini mengggunakan sensor DS18B20 untuk mendeteksi Suhu dan sensor ultrasonik untuk air flow. Komponen yang digunakan diantaranya Atmega 2560 sebagai mikrokontroller, LCD 4 × 20, delphi sebagai tampilan PC, sd card sebagai penyimpanan data dan modul bluetooth HC-05 untuk pengiriman data dari Arduino ke Delphi.

\section{2) Eksperimen}

Dalam penelitian ini dilakukan pengukuran keluaran dari sensor DS18B20 dan ultrasonik berupa data desimal digital pada serial monitor. Pengukuran ini bertujuan untuk mengetahui data pada output DS18B20 dan ultrasonik dan di masukkan dalam rumus program kedua sensor tersebut. Peneliti melakukan pengukuran suhu dan air flow pada baby incubator dengan alat pembanding INCU test II.

\section{B. Blok Diagram}

Ketika tombol power ditekan, maka baterai akan menyuplai tegangan keseluruh rangkaian sehingga, sensor suhu 1, 2, 3, 4, aliran udara, kelembaban, dan kebisingan akan aktif. Setelah itu tekan tombol Start yang dikontrol melalui PC maka sensor akan memulai pembacaan. Kemudian masuk ke port ADC pada IC Arduino yang sudah diberi program dan diolah sedemikian rupa sehingga mendapatkan hasil (output) yang dikirimkan ke PC melalui Bluetooth HC05 ataupun berupa data yang langsung tersimpan di SD Card.

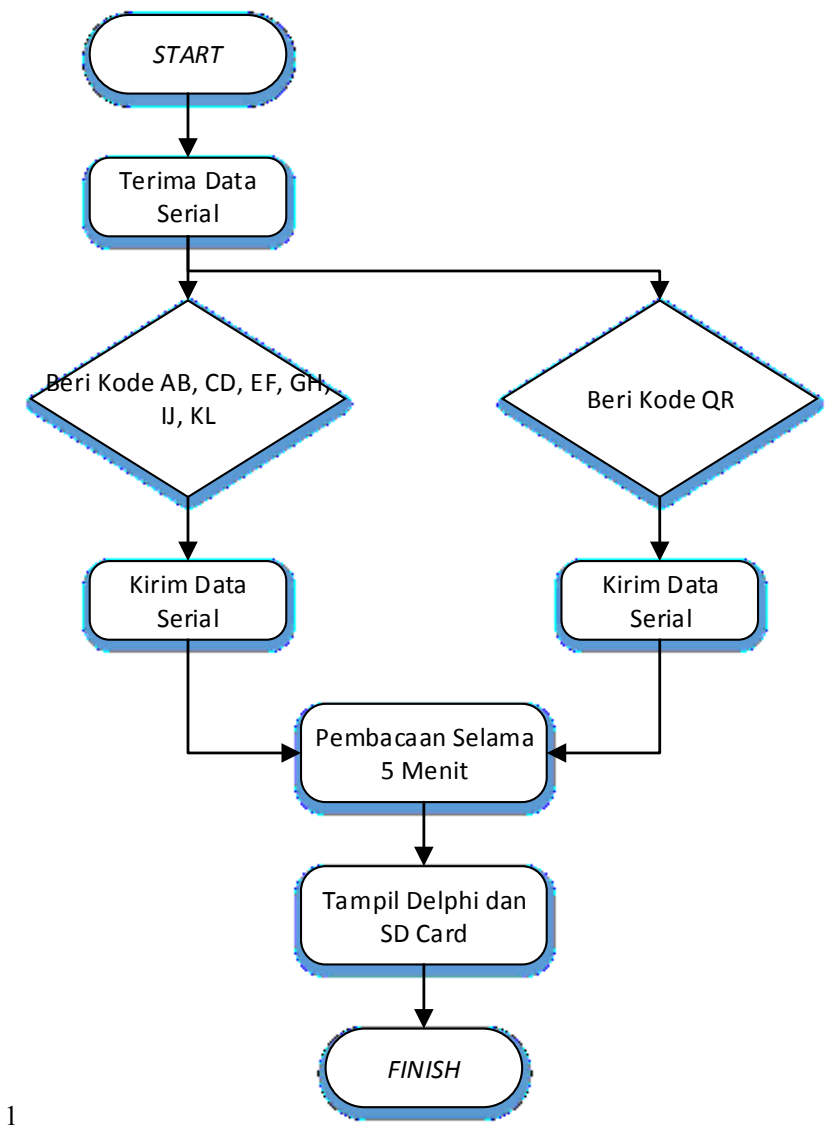

Gambar 1 Diagram Alir Receiver

\section{Flowchart}

Pada diagram alir transmitter setelah dilakukan inisialisasi, dilakukan pembacaan sensor kemudian dilakukan konversi. 
Untuk suhu dari T1, T2, T3, T4, T5, TM diberikan kode "AB, $\mathrm{CD}, \mathrm{EF}, \mathrm{GH}, \mathrm{IJ}, \mathrm{KL}$ " dan air flow diberikan kode "QR" kemudian dilakukan pengiriman oleh transmitter (Bluetooth HC-05) ke receiver (Bluetooth $P C$ ).

Pada diagram alir receiver setelah dimulai, Receiver akan menerima data serial sesuai dengan yang dikirimkan oleh transmitter. Kemudian, data serial tersebut akan dikonversi untuk dikirim ke aplikasi delphi dan SD card secara bersamaan setiap 6 menit sebanyak 6 kali pembacaan untuk ditampilkan pada aplikasi dengan menggunakan aplikasi delphi sesuai dengan kode masing-masing.

\section{Rangkaian Digital}

\section{1) Rangkaian sensor DS18B20}

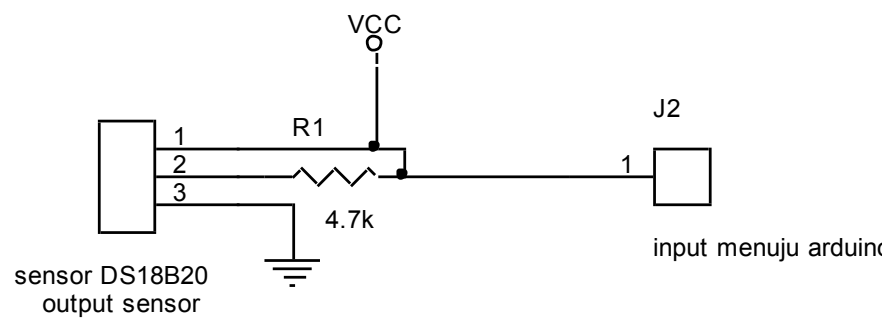

Gambar 2 Rangkaian sensor DS18B20

Rangkaian diatas merupakan rangkaian untuk thermometer contact terdiri dari DS18B20 sebagai slave dan rangkaian mikrokontroler sebagai master. Mikrokontroler dihubungkan dengan DS18B20 melalui pin D7 arduino.

\section{2) Rangkaian sensor Ultrasound}

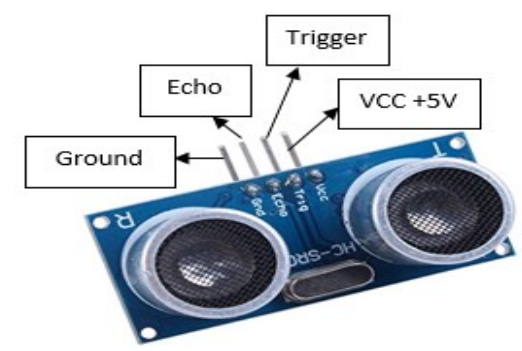

Gambar 3 Rangkaian sensor Ultrasound

Sensor Air Flow menggunakan sensor ultrasonik. Pada sensor ultrasonik ini terdapat empat kaki yaitu $\mathrm{VCC}+5 \mathrm{v}$, Trigger yang berupa pin digital ( PWM), Echo yang merupakan pin digital, dan ground. Pada penggunaan sensor Air Flow ini menggunakan pin digital sebaga ioutputannya.

3) Minimum Sistem

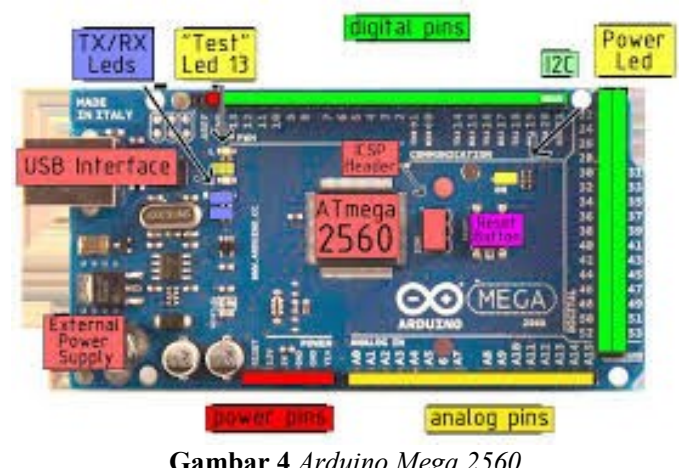

Rangkaian Minimum Sistem yang ditunjukkan pada gambar 6 digunakan untuk pengolahan data dari output masing-masing sensor. Serta digunakan untuk pemograman dan pengiriman data dengan bluetooth. Output dari sensor DS18B20 dihubungkan pada pin D7 dan Air Flow dengan memberikan in out tegangan max 5 volt pada pin digital 10,11 , 28, dan 30 .

\section{4) Modul Bluetooth}

Modul Bluetooth yang digunakan dalam alat ini adalah HC-05. Modul Bluetooth ini digunakan untuk mengirimkan data dari hasil pembacaaan sensor ke android. Modul Bluetooth terkoneksi ke Mikrokontroller dengan menghubungkan pin TX Mikrokontroller ke pin RX Bluetooth dan sebaliknya, pin RX Mikrokontroller ke pin TX Bluetooth.

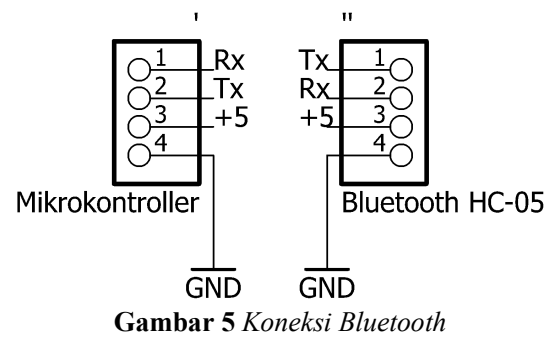

III. RESULTS

Pada penelitian ini telah dilakukan uji coba pada alat secara langsung pada baby incubator untuk mengukur suhu dan air flow. Peneliti juga melakukan pengukuran dengan menggunakan INCU test II sebagai alat pembanding.

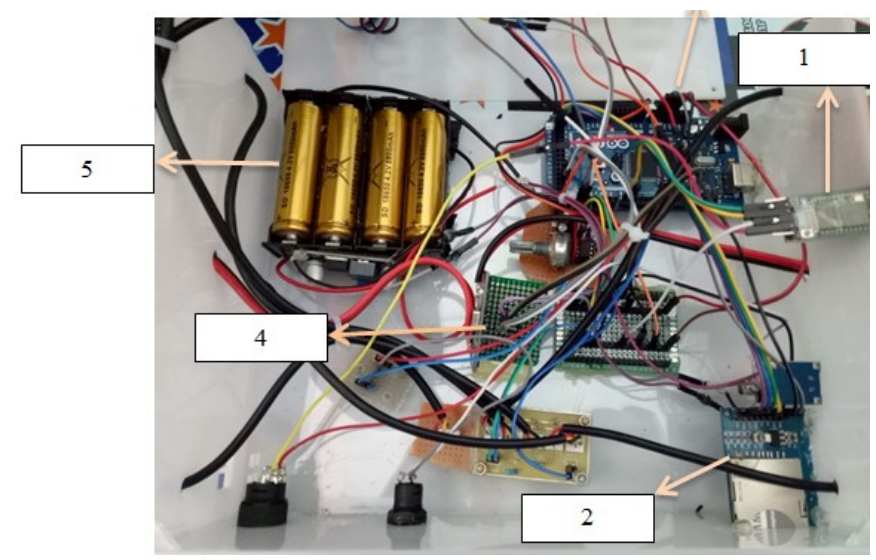




\section{1) Desain Modul}

Gambar 6 Desain Rangkaian

Gambar yang ditunjukan pada gambar 8 merupakan gambar rangkaian modul incubator analyzer. Didalam rangkaian tersebut terdapat beberapa sensor yaitu sensor DS18B20 (suhu), ultrasound HCR04 (Air Flow), dht22 (kelembaban), analog sound sensor (kebisingan). Dirangkaian tersebut terdapat baterai yang berfungsi sebagai supply daya keseluruh rangkaian. Arduino ATMega 2560 berfungsi sebagai prosesor dalam rangkaian agar rangkaian berjalan sesuai keinginan. Sedangkan Bluetooth $\mathrm{HC}-05$ berfungsi untuk menghubungkan modul ke PC untuk mengirim data-data yang terbaca oleh sensor kemudian ditampilkan pada Delphi.

\section{2) Listing Program untuk Arduino}

Listing program Parameter Suhu DS18B20 yang ditunjukkan pada Listing program 1 dan program pembacaan Program Untuk Airflow yang ditunjukan pada Listing program 2.

Listing program 1. Program Parameter Suhu DS18B20

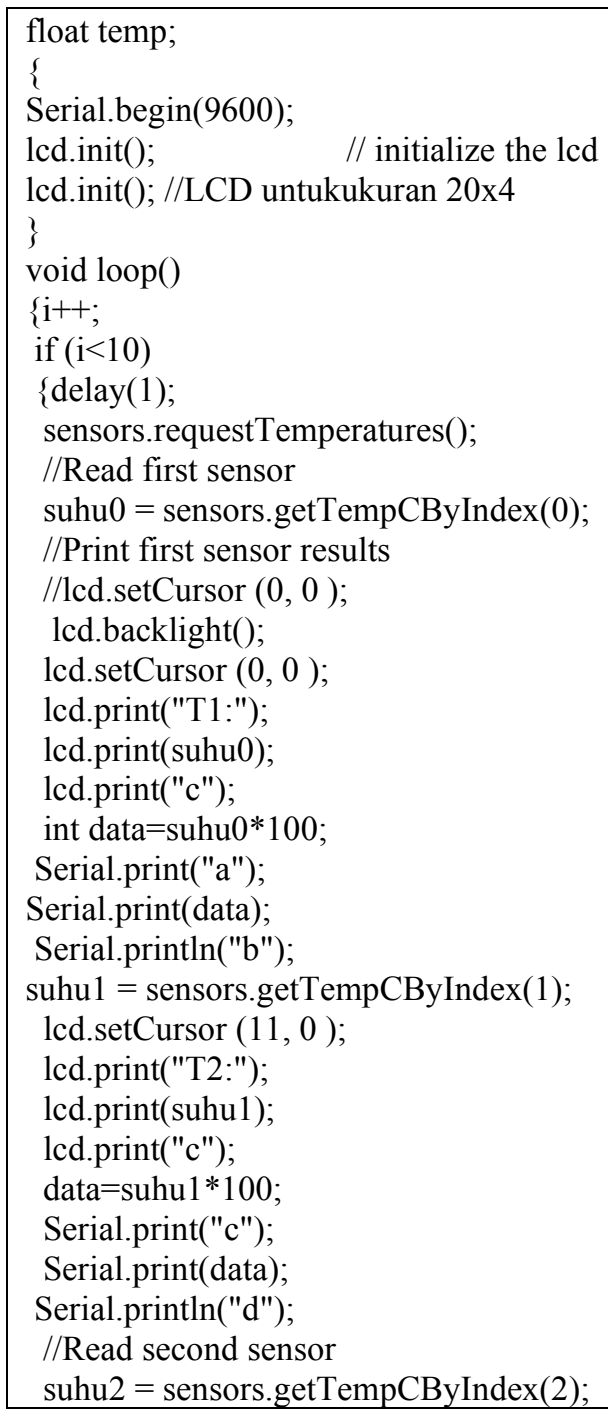

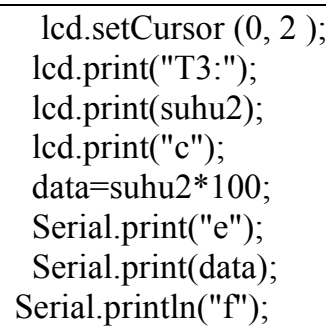




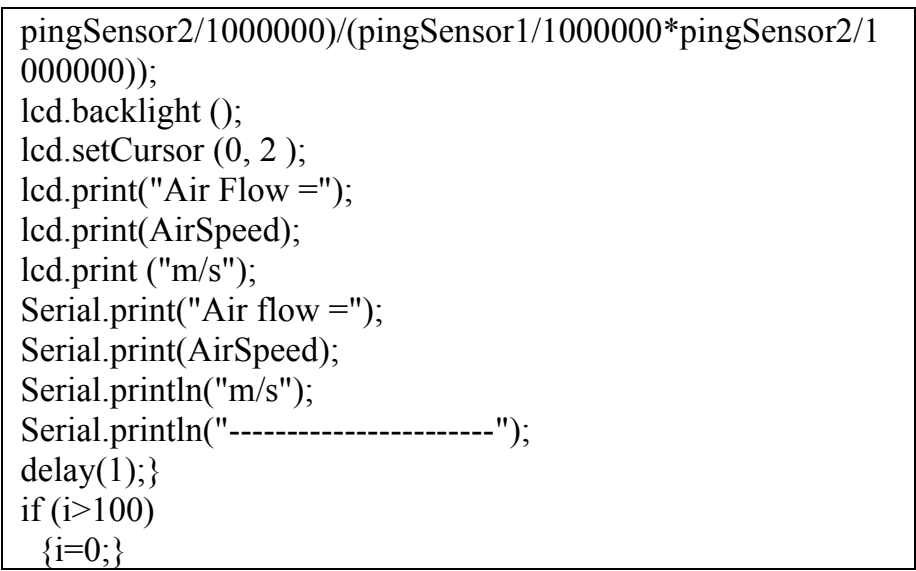

3) Listing Program pada Aplikasi Delphi

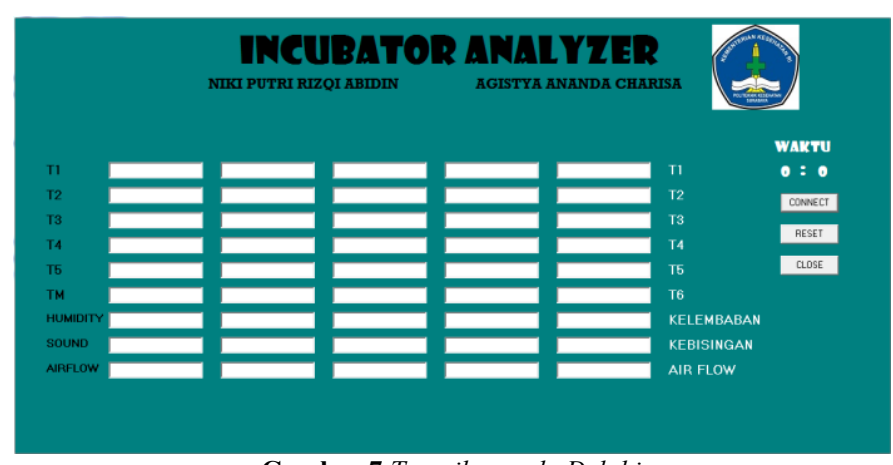

Gambar 7 Tampilan pada Delphi

Tampilan pada PC berupa Delphi dengan 5 kali pengukuran untuk setiap parameter, dengan pengiriman melalui bluetooth HC-05 dari modul. Pada Bluetooth HC-05 yang dipasang pada modul dengan menyambungkan rx ke tx, tx ke rx dan tersambung dengan $+5 \mathrm{~V}$ DC dan Bluetooth eksternal yang terkoneksi pada laptop sudah aktif dengan otomatis. Kemudian melakukan pairing atau menyambungkan antara Bluetooth HC-05 dan Bluetooh eksternal.

a) Program Delphi parameter Suhu

procedure TForm1.ComDataPacket1Packet(Sender:
TObject; const Str: String);
Var
E,dataAdc: integer;
Suhu1:Real;
begin
Val (Str,dataAdc,E);
if $\mathrm{E}=0$ then begin

Suhu:= dataAdc/100;

label11.Caption:= floattoStr(Suhu1);

end;

end;

Keterangan :

- TForm1.ComDataPacket1Packet(Sender: TObject; const Str: String); merupakan perintah untuk memulai jalannya data Suhu T1

- Var E,dataAdc:integer;Suhu1:Real; merupakan perintah inisialisasi T1

- label11.Caption:=floattoStr(Suhu1); merupakan perintah agar data yang masuk di delphi ditampilkan di label 11

\section{a) Program Delphi Untuk Airflow}

procedure TForm1.ComDataPacket9Packet(Sender:

TObject; const Str: String);

Var

E,dataAdc: integer;

airflow:Real;

begin

Val (Str,dataAdc,E);

if $\mathrm{E}=0$ then begin

AirFlow:= dataAdc/100;

label19.Caption:= floattoStr(Airflow);

end;

end;

Keterangan :

- TForm1.ComDataPacket9Packet(Sender: TObject; const Str: String); merupakan perintah untuk memulai jalannya data airflow

- Var E,dataAdc:integer;airflow:Real; merupakan perintah inisialisasi,

- label18.Caption:=floattoStr(airflow); merupakan perintah agar data yang masuk delphi ditampilkan di label 19

\section{4) Hasil Pengukuran Tes Point pada Serial Plotter Arduino}

Untuk rangkaian thermometer contact terdiri dari DS18B20 sebagai slave dan rangkaian mikrokontroler sebagai master. Mikrokontroler dihubungkan dengan DS18B20 melalui pin D7, dimana pengukuran menggunakan sensor DS18B20 untuk mengukur suhu ruang pada baby incubator. 


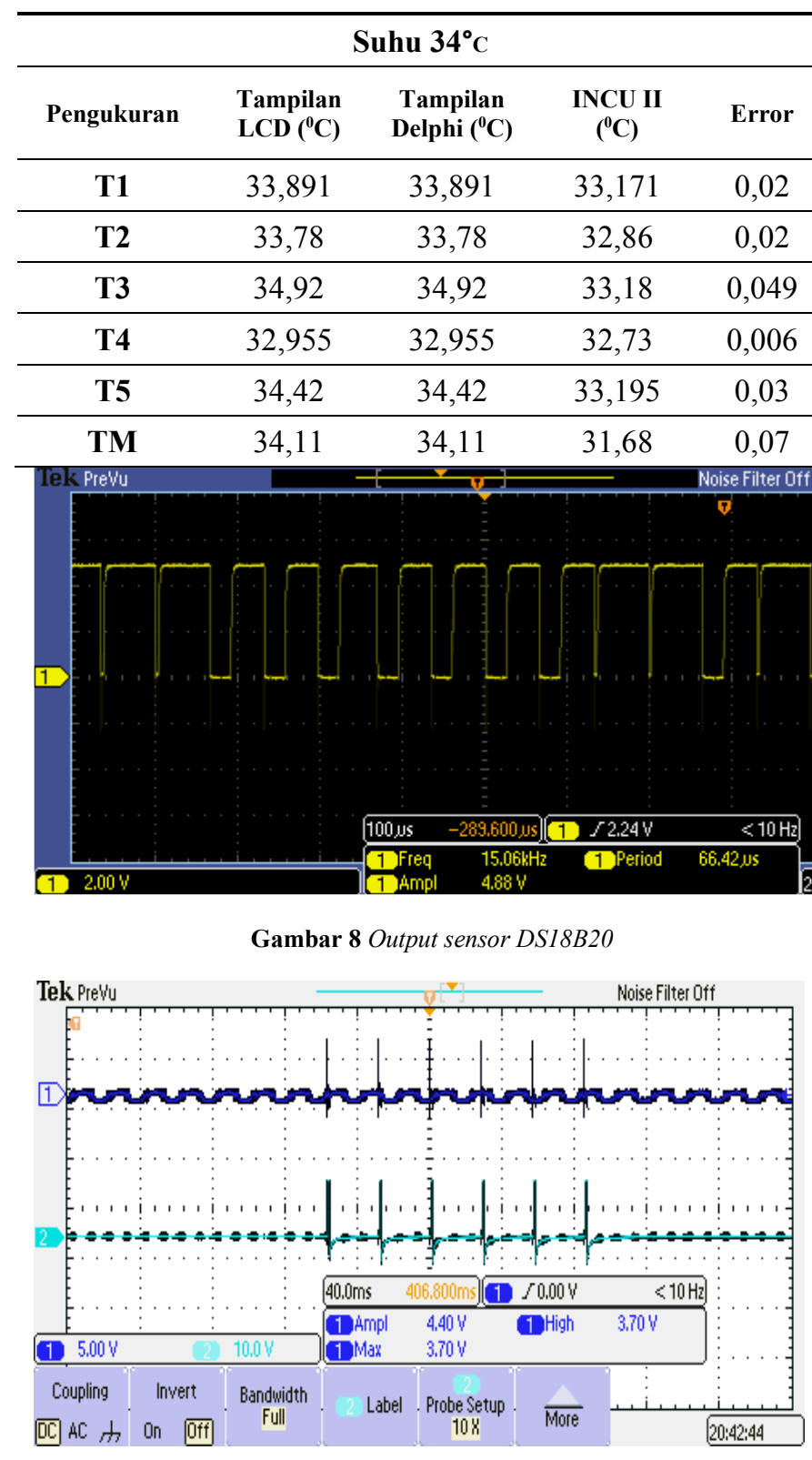

Gambar 9 Output sensor Airflow

Pada gambar diatas menunjukkan hasil pengukuran output dari ultrasound sensor pada kondisi airflow $0,4 \mathrm{~m} / \mathrm{di}$ luar ruang baby incubator.

\section{5) Nilai Error DS18B20}

Hasil pengukuran DS18B20 pada setting suhu $34^{\circ} \mathrm{C}$

TABLE I. PERBANDINGAN NILAI ERROR UNTUK PARAMETER SUHU DENGAN INCU TEST II.

Berdasarkan hasil pengukuran menggunakan INCU TEST II sebagai alat pembanding didapatkan hasil yang berbeda/ rdapat selisih nilai. Nilai error yang didapat paling besar lalah $0,07 \%$ dan paling kecil adalah $0,006 \%$. Nilai rata -rata ror dari hasil pengukuran adalah $0,0325 \%$.

Nilai Error Ultrasound

asil pengukuran Ultrasound pada setting suhu $34^{\circ} \mathrm{C}$

BLE II. PERBANDINGAN NILAI ERROR UNTUK PARAMETER AIRFLOW NGAN INCU TEST II.

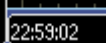

\begin{tabular}{cccc}
\hline \multicolumn{4}{c}{ Sensor Airflow } \\
Pengukuran & $\begin{array}{c}\text { Tampilan } \\
\text { LCD }\left({ }^{0} \mathrm{C}\right)\end{array}$ & $\begin{array}{c}\text { Tampilan } \\
\text { Delphi }\left({ }^{\circ} \mathrm{C}\right)\end{array}$ & $\begin{array}{c}\text { INCU II } \\
\left({ }^{0} \mathrm{C}\right)\end{array}$ \\
\hline 1. & 0,25 & 0,25 & 0,1 \\
\hline 2. & 0,25 & 0,25 & 0,1 \\
\hline 3. & 0,25 & 0,25 & 0,1 \\
\hline 4. & 0,25 & 0,25 & 0,1 \\
\hline 5. & 0,25 & 0,25 & 0,1 \\
\hline 6. & 0,25 & 0,25 & 0,1 \\
\hline Rata-rata & 0,25 & 0,25 & 0,1 \\
\hline Error $(\%)$ & & 0,6 & \\
\hline
\end{tabular}

Berdasarkan hasil pengukuran menggunakan INCU TEST II sebagai alat pembanding didapatkan hasil yang berbeda / terdapat selisih nilai. Nilai error yang dihasilkan adalah $0,6 \%$. Hasil antara modul dengan Incubator Test II yang digunakan sebagai alat pembanding memiliki hasil dengan perbandingan nilai yang sangat jauh. Karena perbedaan bahan turut mempengaruhi tingkat pengambilan air flow dan tingkat sensitivitas.

\section{DISKUSI}

Pengukuran Incubator Analyzer dilakukan langsung pada Baby Incubator dan dibandingan dengan alat INCU test II. Nilai rata - rata error yang didapatkan dari pengukuran suhu antara modul dengan INCU test II yaitu 0,071372741\%. Sedangkan untuk Air Flow didapatkan error sebesar 0,6\%. 


\section{KESIMPULAN}

Berdasarkan hasil pembahasan dan tujuan pembuatan modul dapat disimpulkan bahwa modul ini dapat menampilkan hasil pengukuran suhu dan air flow yang telah diolah dengan program arduino yang hasilnya ditampilkan pada LCD 4 × 20 dan pada aplikasi delphi. Aplikasi delphi yang telah dibuat juga dapat bekerja dengan baik untuk menampilkan data yang telah diterima dari mikrokontroler melalui Bluetooth HC-05.

\section{SARAN}

Buat box lebih kecil lagi sehingga lebih mudah untuk pengambilan data ketika dibandingkan dengan gold standart. Tambahkan pengolahan data otomatis melalui microsoft excel agar operator tidak melakukan perhitungan dan pengolahan data secara manual. Perbaruhi tampilan data di SD Card agar lebih menarik untuk ditampilkan. Mengganti sensor air flow dengan sensor yang memiliki tingkat akurasi yang lebih tinggi dai sensor sebelumnya.

\section{Daftar Pustaka}

[1] Apriliani Puspita, "RANCANG BANGUN ALAT UKUR KALIBRATOR SUHU MENGGUNAKAN DS18S20," no. Diii, pp. 1-6, 2010.

[2] Fluke Biomedical, "INCU incubator analyzer." .

[3] Imro'ah Dyah Sulistya, "Seminar Tugas Akhir Mei 2015," Incubator Anal. Portabel Dilengkapi dengan Pengiriman Data Melalui Bluetooth Tampil Android, pp. 1-9, 2015. 